\title{
Сулейманов А. А.
}

\section{ЭТНИЧЕСКАЯ ИДЕНТИЧНОСТЬ ЮКАГИРОВ ЯКУТИИ В НАУЧНОМ ДИСКУРСЕ XIX - НАЧ. XXI В.}

В работе на основе анализа научной литературы и архивного материала, в том числе, впервые вводимого автором в научный оборот, представлены основные положения, которые были выработаны участниками важнейших исследовательских инициатив XIX - нач. XXI в. по вопросам, относящимся к этнической идентичности юкагиров Якутии. В связи с этим проанализирована динамика наблюдений исследователей за состоянием ряда маркеров, включая «чистоту крови», уровень владения родным языком, самобытность хозяйственной деятельности и культуры, самосознание. Установлено преобладание «негативного» тренда на протяжении большей части рассмотренного периода в оценке учеными перспектив существования юкагиров в менявшихся условиях жизнедеятельности и сохранения ими своей этнической самобытности. В основе такого подхода лежал аккумулированный исследователями материал о неуклонной деградации комплекса объективных признаков, обусловленной, прежде всего, интенсивными ассимиляционными процессами, а впоследствии также и процессами глобализации. Вместе с тем, отмечены важнейшие изменения в позиции ученых, произошедшие в последние десятилетия и сопровождавшиеся ростом внимания к субъективным факторам в функционировании этнической идентичности. Кроме того, отмечено значение деятельности ученых в конструировании этнического самосознания современных юкагиров.

Ключевые слова: коренные народы Арктики, юкагиры, Якутия, научные исследования, экспедиции, этническая идентичность, ассимилящиия.

Юкагиры - один из древнейших аборигенных народов, проживающих в Российской Арктике. Считается, что к моменту прихода русских на территорию Якутии в XVII в. юкагиры населяли обширное пространство от Лены до Анадыря, а их численность составляла около 5 тысяч человек. В настоящее время в республике проживают представители двух локальных групп этноса, насчитывающих порядка 1300 чел. - тундренные (места компактного проживания: села Андрюшкино и Колымское Нижнеколымского района) и лесные (с. Нелемное Верхнеколымского района) юкагиры, которые в определенной степени сохранили язык, традиционные элементы культуры и хозяйственной деятельности.

Очевидно, что значительно интенсифицировавшиеся в последние десятилетия процессы глобализации, «стирания» границ и унификации наибольшие вызовы в плане сохранения этнической «самости» представляют, прежде всего, для таких небольших народов, как юкагиры. В этой связи, безусловно, научное изучение различных аспектов этого вопроса, включая функционирование этнической идентичности, является одной из актуальных задач современного североведения.

Несмотря на то, что этническая идентичность остается относительно новой и пока явно недостаточно разработанной проблематикой в отечественной историографии, тем не менее, представляется возможным проследить наблюдения исследователей за теми маркерами, которые принято относить к этническим признакам: происхождение, владение родным языком, сохранность традиционной хозяйственной деятельности и самобытной культуры, а также самосознание.

Начало формирования научного представления о языке, истории и культуре юкагиров, как известно, относится к XVIII в. Разрозненные сведения об этом этносе были представлены в работах участников исследований Д. Г. Мессершмидта 1720-1727 гг. и Второй Камчатской экспедиции 1733-1744 гг., а руководитель Северо-восточной экспедиции 1785-1793 гг. И. И. Биллингс является автором первого этнографического описания юкагиров (Ширина, 2001: 14-56). 
Первые же научные свидетельства по интересующей нас проблематике относятся уже к XIX столетию, а именно к работам, проведенным в рамках Колымской экспедиции 18201824 гг., основной задачей которой было изучение северо-восточного побережья Сибири. Поскольку участники экспедиции длительное время провели в низовьях Колымы, им удалось произвести подробные наблюдения за жизнью местного населения, его обычаями, а также лингвистической ситуацией (Ширина, 2001: 84-85). В том числе, руководитель экспедиции Ф. П. Врангель зафиксировал активные ассимиляционные процессы, происходившие среди юкагиров, проживающих по правому притоку Колымы - р. Анюй. Они отказались от кочевого образа жизни, приняли христианство, перешли на использование русского языка и, как отметил будущий российский адмирал, «постепенно утрачивают свою народность, нравы и обычаи» (Врангель, 1948: 218-222).

Ко времени изысканий Чукотской экспедиции 1868-1870 гг. Г. Л. Майделя анюйские юкагиры уже «совершенно забыли свою родную речь и приняли как язык, так и образ жизни русских». Аналогичные ассимиляционные процессы Г. Л. Майдель зафиксировал также в низовьях Колымы и на Омолоне (Майдель, 1894: 62-63, 450).

Рассматривая историю аккумулирования исследователями тех или иных материалов, касающихся различных сторон функционирования этнической идентичности юкагиров, естественно, нельзя не остановиться на изысканиях В. И. Иохельсона, по праву считающегося человеком, фактически «открывшим» юкагирский этнос для науки.

В 1895-1897 гг. и 1901-1902 гг. В. И. Иохельсон осуществил исследования в десятках стойбищ якутов, чукчей и юкагиров. При этом «с отдельными родами юкагирского племени, разбросанными на громадном расстоянии между рр. Колымой и Яной» он, по собственному признанию, «жил и странствовал более двух лет» (Иохельсон, 1900: 152).

Одним из базовых положений, разработанных В. И. Иохельсоном, был вывод о значительной степени смешения юкагиров с тунгусами ${ }^{1}$. Данный факт, в частности, по его признанию, затруднял определение реальной этнической принадлежности различных родов аборигенных этносов, зафиксированных тогда на севере Якутии. Используя сведения документальных источников, В. И. Иохельсон назвал 15 из них, представителей которых можно было отнести к юкагирам и т.н. «юкагиризированным тунгусам». Этот термин был специально введен исследователем для обозначения ряда теснейше связанных между собой в этнокультурном отношении сообществ тунгусов и юкагиров, кочевавших тогда на севере Якутии (Иохельсон, 2005: 92-103).

О значительной активности ассимиляционных процессов говорили и приведенные В.И. Иохельсоном данные переписи населения 1897 г.: только 126 юкагиров («47 в колымской тундре и 79 на реках Ясачная и Коркодон») владели юкагирским языком как родным, тогда как для 966 им был уже тунгусский (Иохельсон, 2005: 90-105).

Наиболее отчетливо эта мысль была выражена при характеристике антропологического типа юкагиров - В. И. Иохельсон и его супруга Д. Л. Иохельсон-Бродская провели первые в истории работы по сбору физико-антропологических сведений среди представителей этноса. Всего ими было обследовано 100 человек (Иохельсон, 2005: 59-62).

В результате этих изысканий были определены особенности физического типа юкагиров. При этом В. И. Иохельсон сделал характерную ремарку о сложности выявления первичного,

\footnotetext{
${ }^{1}$ Эвенов (ламутов) и эвенков (тунгусов) В. И. Иохельсон считал разными группами одного народа - тунгусов. Следует отметить, что подобная точка в конце XIX - нач. XX в. была широко распространена. Только с 1931 г. в официальных документах стали употребляться самоназвания этих двух народов. Так как грань между современными понятиями «эвенский» и «эвенкийский» в исследованиях В. И. Иохельсона прослеживается достаточно сложно, чтобы не искажать данные первоисточника, в представленной работе сохранены употребляемые ученым этнические термины.
} 
«чистого» юкагирского типа из-за, происходящего, по его мнению, вырождения народа и ассимиляционных процессов: «современные юкагиры настолько сильно смешались с соседними народами..., что очень трудно говорить о юкагирском типе... Г-же Иохельсон, сделавшей антропометрические замеры..., под рубрикой «юкагиры» пришлось поместить тунгусов и ламутов, живущих среди юкагиров или по соседству, так как они в основном были смешанно-брачными» (Иохельсон, 2005: 51).

Основной труд В. И. Иохельсона, подготовленный по результатам экспедиций 1895 1897 гг. и 1901-1902 гг., «Юкагиры и юкагиризированные тунгусы» с полным правом мог бы получить и название «Реквием по юкагирам». Через всю работу явственно прослеживается мысль автора о скором и неминуемом исчезновении юкагиров вследствие утраты ими своих этнических особенностей и физического вымирания (один из родов юкагиров, например, полностью погиб в период между двумя экспедициями исследователя из-за голода). В частности, В.И. Иохельсон ее страницах можно встретить и фразу о том, что «юкагиры не имеют будущего» (Иохельсон, 2005: 24).

Практически одновременно с В. И. Иохельсоном приступил к историко-этнографическим наблюдениям среди юкагиров Н. Н. Березкин. В разное время этот человек работал учителем, земским заседателем, помощником окружного исправника и окружным исправником, уполномоченным по заготовке теплой одежды, транспорту и устройству трактовых станций в Олекминском, Колымском и Верхоянском округах. Таким образом, Н. Н. Березкин не был профессиональным ученым, а его исследования носили скорее любительско-краеведческий характер - во всех местах своей службы, по данным С. И. Бояковой, он старался собирать материалы по истории, географии и полезным ископаемым подотчетных территорий (Боякова, 2011: 80-81). Именно ввиду значительного объема и определенной уникальности собранных исследователем сведений о юкагирах, очевидного скрупулезного и ответственного отношения к их подаче, тесных связях с бывавшими на Колыме учеными (известно, что Н. Н. Березкин помогал экспедициям И. Ф. Молодых, Н. П. Вагнера, а также С. В. Обручеву, который назвал его «знатоком Колымского края»), проведенные им изыскания рассматриваются в данной статье.

До сих пор неопубликованная работа Н. Н. Березкина «Юкагиры» хранится в архиве Музея антропологии и этнографии им. Петра Великого РАН (Кунсткамера). Судя по тексту рукописи, ее автор в течение 1893-1934 гг. проводил в северных районах Якутии (Верхоянье, бассейны рек Алазея, Булун, Индигирка, Колыма и Яна) опрос юкагирских старейшин, местных чиновников, а также рядовых представителей русских арктических старожилов, эвенов, эвенков, юкагиров и якутов (Боякова, 2011: 81).

На основе этих опросов, а также собственных наблюдений Н. Н. Березкин представил несколько интереснейших сюжетов из прошлого юкагиров и их современной жизни, часть из которых имеет непосредственное отношение к рассматриваемой проблематике.

В частности, мобилизованный исследователем материал подтверждал сведения о глубоких ассимиляционных процессах, происходивших в результате все более тесных контактов юкагиров с русскими, эвенами и якутами. Эти процессы, естественно, вели к утрате самобытности юкагиров и их первоначального физического типа. В качестве подтверждения своих наблюдений Н. Н. Березкин привел свидетельства информантов. Так, староста Нижне-Колымского юкагирского общества М. Татаринов в 1897 г. сообщил о том, что все его подопечные «обруселые», «незнающие своего родного юкагирского языка», проживают вместе с русскими в рыбацких заимках, «в таких же, как и у них срубленных домах» (НА МАЭ РАН. Ф. К-V. Оп. 1. Д. 6. Л. 28). Другой рассказчик, тундренный юкагир К. К. Третьяков, спустя десять лет сообщал: «мы здесь совершенно утратили все юкагирское. Перемешалась наша кровь с тунгусской и даже чукотской. Чистокровных юкагиров в тундре нет, не говоря уже о быте, обычаях и языке. Мы стали ничем не отличаемы от тунгусов. Утрата юкагирами национального 
облика особенно резко сказалась после эпидемии оспы ${ }^{2} .$. Нас в семье было 10 человек, из которых остались в живых я и мой брат, остальные умерли» (НА МАЭ РАН. Ф. К-V. Оп. 1. Д. 6. Л. 32-33).

Еще один вклад в научную «копилку», касающуюся проблемы ассимиляции юкагиров, внесли проводившие в 1939 г. в юкагирских селениях на реках Коркодон и Нелемная изыскания научный сотрудник Охотско-Колымского краеведческого музея К. К. Дидык и краевед В. Кривошеин.

Проведенный исследователями опрос местных жителей показал, что из 42 информантов, лишь у 12 среди ближайших предков (до четвертого колена) были только юкагиры, в остальных случаях наблюдалась смешение с эвенами и якутами. Об этом же свидетельствовали и осуществленные физико-антропологические наблюдения. Составляя на их основе антропологическую характеристику юкагиров, К. К. Дидык и В. Кривошеин, как и ранее супруги Иохельсон, установили значительную степень смешения этноса с эвенами, а также якутами. Полученные же исследователями сведения о происходящих социолингвистических процессах, показали, что, несмотря на сохранность и повседневное употребление юкагирами своего родного языка, представители этноса в разговорах часто переходили на якутский, «которые многие знали лучше, чем свой» (НА МАЭ РАН. Ф. К-У. Оп. 1. Д. 27. Л. 1-33; Д. 47. Л. 1-14).

Новый импульс исследование различных сторон жизнедеятельности юкагиров, включая интересующие нас вопросы, получило после создания в Якутске первоначально базы (1947 г.), а затем филиала (1949 г.) Академии наук СССР в рамках которых осуществлял свою деятельность Институт языка, литературы и истории (ИЯЛИ)

В первой половине 50-х гг. XX в. под руководством научного сотрудника ИЯЛИ И. С. Гурвича были проведены этнографические исследования в большинстве северных районов Якутии. Так, в 1951 г. состоялась экспедиция в Нижне- и Среднеколымский районы Якутии. Изыскания продолжались около полугода, а общая протяженность проделанных исследователями маршрутов превысила 3000 км (Гурвич, 1952: 200).

В ходе экспедиции, в том числе, были организованы работы в основном ареале сосредоточения тундренных юкагиров - селах Колымское и Андрюшкино Нижнеколымского района, а также в поселениях на реках Омолон и Анюй (Гурвич, 1952: 200-201).

Проведенные исследования выявили хорошую степень сохранности у тундренных юкагиров своего родного языка, представления о себе как об особом этносе - «одулах», а также ряда самобытных особенностей в области обрядов и фольклора. Вместе с тем, И. С. Гурвич отметил, что тесные этнокультурные связи юкагиров со своими историческими соседями эвенами привели к «полному восприятию одулами эвенского типа жилища, эвенского покроя одежды, обуви, усвоению эвенского образа жизни» (РФ АЯНЦ СО РАН. Ф. 5. Оп. 1. Д. 231. Л. 13-14). Анюйские же и омолонские юкагиры, по данным ученого, окончательно слились с русским населением (РФ АЯНЦ СО РАН. Ф. 5. Оп. 1. Д. 231. Л. 14).

Развитие эти изыскания получили в 1959 г. в рамках Юкагирской комплексной экспедиции, научным руководителем которой являлся И. С. Гурвич, перешедший к тому времени на работу в московский Институт этнографии им. Н. Н. Миклухо-Маклая АН СССР. Следует отметить, что по своему значению в истории научного изучения юкагиров экспедиция 1959 г. сопоставима только с исследованиями В. И. Иохельсона. В ее рамках сотрудники ИЯЛИ, Института этнографии и Ленинградского отделения Института языкознания АН СССР провели исследования в большинстве из мест компактного проживания юкагиров в Нижнеколымском,

\footnotetext{
2 Первая известная эпидемия оспы среди юкагиров началась в 1663 г. После второй - 1692-1693 гг. - численность юкагиров сократилась почти вдвое. В XVIII-XIX вв. эпидемии оспы, по данным А. Аргентова, повторялись через каждые 70-80 лет. Согласно сведениям В. А. Туголукова, эпидемия оспы 1889 г., о которой, по-видимому, говорил К. К. Третьяков, унесла жизни 10,5 тыс. человек.
} 
Аллаиховском и Верхнеколымском районах Якутии, а также в Среднеканском районе Магаданской области.

В результате ученым удалось собрать достаточно солидный материал, характеризующий происходившие в среде юкагиров этнические процессы. В частности, проведенные опросы местного населения и анализ похозяйственных списков показали «далеко зашедший» процесс смешения представителей этноса с эвенами и чукчами. При этом его значительная интенсификация, по мнению исследователей, произошла незадолго до проведения изысканий - в конце 40-х - 50-е гг. ХХ в. под влиянием осуществляемой на Севере политики коллективизации и поселкования. Итогом этого процесса стала метисация практически всех юкагиров, подавляющее большинство которых ко времени экспедиции было распределено по смешанным семьям (РФ АЯНЦ СО РАН. Ф. 5. ОП. 1. Д. 359. Л. 38-39).

Среди других выявленных последствий коллективизации для этнических процессов в Нижнеколымском районе был отмечен интенсивный обмен культурными ценностями: восприятие чукотских приемов выпаса оленей юкагирами и эвенами, чукотской мужской одежды русскими, эвенами, юкагирами и якутами, эвенской женской - чукчами и т.п. В Верхнеколымском же районе коллективизация привела, по мнению исследователей, к высокой степени утраты лесными юкагирами исконных навыков занятий охотой и рыболовством и в целом своей этнокультурной самобытности, а также обезлюдиванием традиционных мест проживания по берегам рек Рассоха и Коркодон. Среди причин такого положения ученые выделили форсированное переселение промыслового населения в крупные поселки и переход к новым отраслям хозяйствования (животноводство, огородничество), значительно менее рентабельных в условиях Севера, чем традиционные промыслы. Кроме того, исследования 1959 г. подтвердили сведения В. И. Иохельсона о полной утрате юкагирами междуречья Яны и Индигирки знания юкагирского языка (АРАН. Ф. 142. Оп. 1. Д. 1201. Л. 18-19).

Параллели между исследованиями В. И. Иохельсона и участников Юкагирской комплексной экспедиции прослеживаются и в оценке «перспектив» юкагиров. Так, на страницах работ И.С. Гурвича и руководителя лингвистического отряда Е. А. Крейновича встречаются характерные ремарки о том, что «процесс угасания» этого этноса остановить не удалось и ученым необходимо успеть исследовать и задокументировать различные проявления его традиционной культуры (НА ИЭА РАН. Ф. 142. Оп. 2. Д. 24. Л. 2; РФ АЯНЦ СО РАН. Ф. 5. Оп. 1. Д. 459. Л. 1).

Еще одним исследователем, мобилизовавшим достаточно репрезентативный материал по рассматриваемой в статье проблематике, был коллега И. С. Гурвича по Институту этнографии АН СССР В. А. Туголуков.

Следует отметить, что этот ученый являлся, главным образом, специалистом по истории и этнографии тунгусоязычных народов нашей страны. Именно как эксперт-тунгусовед В. А. Туголуков подошел к изучению юкагиров.

Полевой и документальный материал ученый собирал летом 1969 и 1970 гг. в поселках Зырянка и Черский, селах Нелемное, Андрюшкино, Ойотунг, а также рыболовецком участке юкагиров на озере Малое Улуро (НА ИЭА РАН Ф. 44. Оп. 12. Д. 1618. Л. 47-59; Ф. 142. Оп. 2. Д. 82. Л. 108-109).

Значительное внимание в ходе изысканий В. А. Туголуков уделил аккумулированию сведений о традиционных видах хозяйственной деятельности: охоте, рыболовстве и оленеводстве; материалов, касающихся мифологии, этнической терминологии, в целом, лингвистической ситуации и, главное для нас - этнических связей и национальной идентификации.

Так, исследователь отметил «частичную сохранность» юкагирского языка у жителей бассейна реки Алазея (с. Андрюшкино) и «практически полную» утрату его знания населением Индигирки. В последнем случае родным языком являлся преимущественно эвенский (эти сведения, таким образом, находились в хорошем соответствии с материалами, полученными 
В. И. Иохельсоном и участниками Юкагирской комплексной экспедиции) (НА ИЭА РАН. Ф. 142. ОП. 2. Д. 82. Л. 113-115).

Примечательно, что в подготовленном по результатам экспедиции отчете В. А. Туголуков на основе анализа выявленных этнонимов, а также иных полевых материалов, пришел к следующему выводу: «в настоящее время говорить о существовании тундровых юкагиров не приходится. В лучшем случае в междуречье Индигирки и Колымы мы находим юкагироязычных тунгусов (на страницах отчета исследователь употреблял и термин В. И. Иохельсона «юкагиризированные тунгусы». - A. C.). Дальнейшая полевая работа должны дать ответ на вопрос, какие местные этнографические группы относятся к эвенкам, а какие к эвенам (ламутам)» (НА ИЭА РАН. Ф. 142. Оп. 2. Д. 82. Л. 114-115).

Однако в опубликованной в 1979 г. монографии «Кто вы, юкагиры?» В. А. Туголуков уже вообще не упоминает понятий «юкагироязычные» или «юкагиризированные» тунгусы и менее категоричен относительно юкагиров Нижнеколымского района - ученый отметил, что ядро этнической группы, «именующей себя одулами и говорящей на тундровом диалекте юкагирского языка», составляют «тунгусы, выходцы с Нижней Лены, женившиеся на юкагирских женщинах» (Туголуков, 1979: 330).

В 1985-1990 гг. в местах компактного проживания юкагиров и эвенов, селах Березовка, Себян-Кюель, Андрюшкино и Нелемное, Институтом цитологии и генетики СО АН СССР были организованы пионерные генетико-демографические изыскания (Донской и др., 1996: 31). Задачами исследований являлись: оценка происходящих микроэволюционных процессов; выявление особенностей генетической структуры популяций двух этносов, а также определение генетических взаимосвязей их представителей с другими коренными народами Севера (Посух, 1992: 41).

На основе анализа данных похозяйственных книг сельских советов, опроса глав и членов семей учеными были составлены расширенные родословные на глубину 3-5 поколений, выяснены имена, возраст, этническая принадлежность супругов, их детей и родителей, причины смерти и возраст умерших. У женщин отдельно собирались сведения о возрасте вступления в брак, числе замужеств, начале и конце репродукции, количестве и исходах беременности. Кроме того, у жителей исследованных населенных пунктов был произведен забор крови (Поcyx, 1992: 42-44).

По итогам изысканий их участница О. Л. Посух разделила каждую из изученных популяций на «чистую», т.е. не смешанную с другими национальностями, и метисированную части. При этом, например, в Нелемном только 8\% юкагиров являлись прямыми потомками юкагирских родов, издавна проживавших в верховьях Колымы. Не многим лучше обстояла ситуация и в Андрюшкино, юкагирское население которого глубоко перемешалось с эвенами (Посух, 1992: 46-47). В результате ученая пришла к достаточно пессимистическим выводам: «Две последние популяции юкагиров уже не воспроизведут себя в будущем: в Нелемном практически полностью последнее поколение - это уже метисы, юкагиры Андрюшкино также почти полностью ассимилированы эвенами, якутами и чукчами... через 1-2 поколения эта древнейшая народность с уникальным эволюционно сложившимся генофондом, уже практически утерявшая свою культуру, язык, традиционный хозяйственный уклад, перестанет существовать как отдельный этнос, полностью “растворясь” среди окружающих народов...» (Поcyx, 1992: 49).

В мае - сентябре 1993 г. в селах Андрюшкино, Колымское и Нелемное проводили исследования члены экономико-социологической экспедиции, организованной якутским Институтом проблем малочисленных народов Севера СО РАН. В реализации инициативы и обработке полученных материалов принимали участие: Ф. С. Донской, Г. Н. Курилов, А. Н. Прокопьев, Я. Г. Слепцов, В. А. Стручков, П. З. Тобуков и Х. Х. Турнин. Основной целью исследований был анализ адаптации юкагиров к рыночным условиям (Донской и др., 1996: 3-4). 
В плане рассматриваемых в данной статье вопросов наибольший интерес представляют осуществленный участниками исследовательской инициативы анализ демографической ситуации и демографических процессов. В частности, они рассмотрели динамику естественного движения юкагиров (рождаемость, смертность, прирост) в течение 1980-1992 гг. и составили характеристику половозрастной структуры. Ученые подтвердили выводы предшественников об активной ассимиляции юкагиров со своими соседями, которая была обусловлена, прежде всего, высоким уровнем смешанных браков (Донской и др., 1996: 27-29). Вот, что писали об этом сами исследователи: «...c 1980 по 1992 гг. из числа юкагиров Колымы обоего пола вступили в брак 57 человек, из них «чисто» юкагирских браков было всего лишь 10,6\%, а смешанных - 89,4\%. Если от общего числа родившихся детей в 1980 г. у 71,4\% отцы являлись представителями другой национальности, то в 1992 г. этот показатель повысился до 77,2\%» (Донской и др., 1996: 29).

Кроме того, в ходе экспедиции было произведено изучение языковой ситуации, показавшее, что только порядка $10 \%$ юкагиров Верхне- и Нижнеколымского районов в той или иной степени владеют юкагирским языком (Курилов, 2006: 6).

Название монографии, опубликованной по итогам экспедиции, - «Проблемы возрождения исчезающих юкагиров» - говорит само за себя. Коллектив ее авторов фактически продолжил «пессимистический» тренд в оценке будущего юкагирского этноса. Его характерной особенностью являлись выводы исследователей об активнейших ассимиляционных процессах, значительном смешении юкагиров с другими народами, неминуемой и близкой утрате ими этнической самобытности. Однако в конце XX в. в научном дискурсе стал активно пробивать себе дорогу более позитивный взгляд.

Одной из первых ласточек в этом плане стали исследования участников Колымской лингвоэтнографической экспедиции, организованных ленинградскими отделениями Института этнографии АН СССР (Кунсткамера) и Института языкознания АН СССР под руководством Г. Н. Грачевой и Н. Б. Вахтина в 1987 г.

Участники данной инициативы, среди прочего, выявили две генеральные тенденции протекания этнических процессов. С одной стороны, шло интенсивное размывание традиционной культуры юкагиров под воздействием явлений, которые бы сейчас отнесли к последствиям глобализации, а исследователи назвали их тогда «интернационализацией». С другой - в полной мере проявлялись и этноконсолидационные процессы, основывавшиеся «отчасти на языке, общности истории и в полной мере на самосознании...» (НА МАЭ РАН. Ф. К-І. Оп. 2. Д. 1528. Л. 33). Последний тезис основывался на выявленных в Нелемном, Андрюшкино и Колымском фактах, среди которых, например, запись детей от смешанных браков юкагирами для того, чтобы «национальность соответствовала среде» или сознательного увеличения численности этноса, а также получения материальных льгот, включая высоко котировавшиеся преференции при поступлении в ВУЗы (НА МАЭ РАН. Ф. К-І. Оп. 2. Д. 1528. Л. 14-74).

В последующий период, характеризовавшийся значительным всплеском внимания ученых к исследованию различных проблем жизнедеятельности юкагиров, подобный подход можно встретить уже в работах целого ряда исследователей: как российских (Л. И. Винокурова, А. И. Егорова, Л. Н. Жукова, Н. В. Плужников, А. А. Сирина, В. В. Филиппова, В. И. Шадрин и др.), так и зарубежных (Р. Виллерслев, С. Оде, Ж. Робер-Ламблен, Г. Фондал, Б. Шишло, Ф. Эндо и др.) (см. напр.: Винокурова, Шадрин, 2006; Филиппова, 2014; Chichlo, 1999), получивших после падения железного занавеса возможность проводить полноценные изыскания в арктических районах нашей страны.

Следует отметить, что возросшая исследовательская активность привела к тому, за последние три десятилетия едва ли найдется полевой сезон, в течение которого целые группы или отдельные ученые не посещали хотя бы одно из мест компактного проживания юкагиров. 
Видимо, вновь именно Г. Н. Грачева была одной из первых, кто отметил значительный «экспедиционный пресс», оказываемый на юкагиров: только в течение 1986-1987 гг. Нелемное посетили три отряда исследователей (НА МАЭ РАН. Ф. К-І. Оп. 2. Д. 1528. Л. 11).

Рассмотреть результаты каждой из реализованных в этот период инициатив, естественно, не позволяют рамки данной статьи. Поэтому представляется целесообразным обобщить основные выводы, сделанные по их итогам.

С одной стороны, полученные учеными материалы, казалось бы, продолжают свидетельствовать об угрозе исчезновения юкагиров - все меньше и меньше из представителей этого этноса владеют родным языком, минимальна их занятость в традиционных отраслях хозяйства, да и сами эти отрасли в условиях глубокого проникновения рыночных отношений и глобализации становятся все менее «традиционными». Фактически «экспортную» направленность приобрели проявления (зачастую возрожденные) традиционной культуры - исполнение произведений фольклора, народных танцев, изготовление предметов быта и промысла, ориентировано, прежде всего, на приезжающие официальные делегации и ученых. Совершенно неминуемым в сложившихся условиях жизнедеятельности юкагиров и их малочисленности стали теснейшие кровнородственные связи с представителями окружающих народов, приведшие к фактической утрате «чистоты крови».

Однако, несмотря на все это, исследователи уже не спешат делать выводы о скором исчезновении юкагирского этноса. Связано данное обстоятельство, прежде всего, с уже отмечавшимся выше изменением акцентов - значительное большее внимание ученые стали уделять субъективным этническим признакам, которые, по их мнению, вышли на первый план в функционировании этнической идентичности юкагиров. По оценке специалистов, в современных реалиях при этнической самоидентификации стали преобладать такие факторы как: социально-экономические (различные социальные льготы, квоты на добычу биоресурсов и т.д.), административные меры органов власти, энергичная деятельность общественных организаций, одним из следствий повышенного внимания которых явился фактический рост престижа этнонима «юкагир» (Шадрин, 2014: 15-17). В этом отношении показательно, что юкагиры стали первым аборигенным этносом в Якутии, представители которого добились принятия закона, расширяющего полномочия органов местного самоуправления в своих муниципальных образованиях - Суктулах (Григорьев, 2011: 110-114).

«На выходе» получилась достаточно парадоксальная ситуация. Например, в результате полевых исследований, проведенных в рамках посвященного юкагирам проекта РФФИ в 2013 г., участником которого являлся и автор представленной статьи, было установлено, что более $80 \%$ опрошенных посчитали знание родного языка «важным» или «очень важным» фактором при определении своей национальной принадлежности (ПМА). Однако одновременно было выявлено, что юкагирским языком владеет лишь 7\% юкагиров. Схожая ситуация наблюдалась и в отношении других базовых объективных этнических признаков - традиционного хозяйства и самобытной культуры (Шадрин, 2014: 12-14). Вместе с тем, это не мешало опрошенным в ходе официальных переписей населения идентифицировать себя как представителей именно юкагирского этноса. В результате статистики фиксируют неуклонный рост численности людей, относящих себя к юкагирам. Если в 1989 г. в Якутии проживало 697 представителей этого этноса, то в 2002 г. уже 1097, а спустя 8 лет - 1281 (Филиппова, 2014: 40-43).

В заключении следует остановиться на еще одном изменении, которое, как представляется, произошло в отношении научного дискурса в последние годы. Как было отмечено, уже три десятилетия в места компактного проживания юкагиров непрерывным ручейком тянутся большие и малые группы ученых из России и других стран мира. Это, конечно же, с одной стороны, привело к определенной усталости представителей этноса от бесконечных интервью и анкетирований и в то же время, возможно, стало еще одним фактором, повысившим престижность именно их национальной принадлежности. «Соседи» юкагиров других националь- 
ностей зачастую не интересуют приезжающих специалистов. Очевидно, сказывается и ежегодное «напоминание» учеными местным жителям о своих исторических корнях. Например, в Чокурдахе был зафиксирован случай, когда местная жительница после получения результатов сделанного исследователями генетического анализа записала свою дочь юкагиркой (Шадрин, 2014: 16). Таким образом, исследователи из беспристрастных наблюдателей этнических процессов, происходивших в среде юкагиров, вероятно, превратились в один из важных факторов конструирования их современного этнического самосознания.

Резюмируя представленный материал, следует отметить, что, начиная с XIX в. в научном дискурсе фиксировалась утрата юкагирами различных элементов своей этнической самобытности. Зачинатель юкагироведения В. И. Иохельсон вовсе пришел к выводу о скором исчезновении этноса. На протяжении прошлого столетия такой пессимистичный взгляд на будущее юкагиров имел среди ученых достаточно широкое распространение. В его основе лежали ожидания тотальной ассимиляции юкагирского народа. В последние годы исследователи продолжают наблюдать фактическую деградацию уровня владения юкагирами родным языком, навыков ведения традиционных отраслей хозяйства и проявлений самобытной культуры. Вместе с тем, в научном дискурсе важное место стал занимать взгляд об определенной условности названных объективных маркеров этнической идентификации в современных реалиях и их замещении рядом субъективных факторов. Однако при всей возможной справедливости такого подхода с представителей органов власти, научного сообщества и общественности не снимается задача по сохранению уникальной юкагирской культуры в условиях глобализации и стремительной трансформации привычного образа жизни.

\section{Список источников и литературы}

Архив Российской академии наук (АРАН).

Боякова С. И. «Знаток Колымского края....»: Н. Н. Березкин о проблемах и перспективах развития Крайнего Севера // Якутский архив. - 2011. - № 3. - С. 80-82.

Винокурова Л. И., Шадрин В. И. Лесные юкагиры Якутии: состояние этнической культуры // Межэтнические взаимодействия и социокультурная адаптация народов севера России. - М.: КоЛеСо, 2006. - С. 75-95.

Врангель Ф. П. Путешествие по северным берегам Сибири и по Ледовитому морю. - М.: Изд-во Главсевморпути, 1948. - 454 c.

Григорьев С. А. Общественно-политическое движение коренных народов Якутии (конец 1980-х - 1990-е гг.). Дис. ... канд. ист. наук. - Якутск: СВФУ, 2011. - 181 с.

Гурвич И. С. Этнографическая экспедиция в Нижне-Колымский и Средне-Колымский районы Якутской АССР в 1951 году // Советская этнография. - 1952. - № 3. - С. 200-209.

Донской Ф. С., Курилов Г. Н., Слепцов Я. Г. и др. Проблемы возрождения исчезающих юкагиров. - Якутск: Северовед, 1996. - $140 \mathrm{C}$.

Иохельсон В. И. Бродячие роды тундры между реками Индигиркой и Колымой, их этнический состав, наречие, быт, брачные и иные обычаи и взаимодействие различных племенных элементов // Живая старина. - 1900. - Вып. 1-4. $654 \mathrm{c}$.

Иохельсон В. И. Юкагиры и юкагиризированные тунгусы. - Новосибирск: Наука, 2005. - 675 с.

Курилов Г. Н. Современный юкагирский язык. - Якутск, 2006. - 280 с.

Майдель Г. Л. Путешествие по Северо-Восточной части Якутской области в 1868-1870 годах. - СПб.: Изд. Императорской Академии наук, 1894. - 599 с.

Научный архив Института этнологии и антропологии им. Н. Н. Миклухо-Маклая РАН (НА ИЭА РАН).

Научный архив Музея антропологии и этнографрии им. Петра Великого РАН (НА МАЭ РАН).

Полевые материалы автора (ПМА), 2013 г.

Посух О. Л. Генетико-демографическое изучение популяций эвенов и юкагиров Якутии // Популяционно-генетическое изучение северных народностей. - Новосибирск: ИЦиГ СО РАН, 1992. - С. 41-65.

Рукописный фонд Архива Якутского научного центра Сибирского отделения РАН (РФ АЯНЦ СО РАН).

Туголуков В. А. Кто вы, юкагиры? - М.: Наука, 1979. - 152 с. 
Филиппова В. В. Юкагиры Якутии: динамика демографических показателей второй половины XX - нач. XXI в. // Казанская наука. - 2014. - № 11. - С. 39-43.

Шадрин В. И. Трансфрормация этнической идентичности юкагиров в современных условиях // Гуманитарные и социальные науки. - 2014. - № 1. - С. 9-19.

Ширина Д. А. Россия: научное исследование Арктики. XVIII в. - 1917 г. - Новосибирск: Наука, 2001. - 191 с.

Chichlo B. Le district de Nijnekolymski: population, renniculture, ethnicité // Sibérie II, Histoire, Culture, Littérature / Ed. by

B. Chichlo. - Paris, 1999. - P. 475-502.

Сулейманов А. А., кандидат исторических наук, с.н.с. отдела истории и этносоциологии.

Институт гуманитарных исследований и проблем малочисленных народов Севера

Сибирского отделения РАН.

Ул. Петровского, 1, Якутск, Россия, 677007.

E-mail: alexas1306@gmail.com

Материал поступил в редакцию 16.02.2018 г.

Suleymanov A. A.

\section{THE ETHNIC IDENTITY OF YUKAGHIRS OF YAKUTIA IN SCIENTIFIC DISCOURSE OF THE XIX - BEG. XXI C.}

On the basis of the review of scientific literature and archive materials that also include the material that is being introduced into scientific discourse for the first time, the fundamental principles are presented these principles concerning the questions of ethnic identity of the Yukaghir of Yakutia were elaborated by the members of the important research initiatives in the XIX - beginning of XXI century. In connection to this there has been made an analysis on dynamics of scholars on the status of a number of markers, that include "purity of blood", the level of proficiency in the native language, distinctness of anthropogenic activities and culture, self-consciousness. The "negative" trend has been predominating through much of the studied period, that was established by the scholars during estimation of the perspectives of the Yukaghir people's existence in the rapidly changing environment and their preservation of the ethnic distinctness. The accumulated research material on steady degradation of a complex of objective signs which was firstly conditioned by the intense assimilation processes and then by the processes of globalization was the basis for this approach. At the same time, the significant changes were noted in the approaches used by scholars; these changes happened in the last decades and they have been accompanied by the increased attention to the subjective factors in functioning of ethnic identity of the Yukaghir. Moreover, the significant role of scholars' activities in designing the ethnic selfconsciousness of the modern Yukaghirs is noticed.

Key words: Indigenous Peoples of the Arctic, Yukaghirs, Yakutia, scientific researches, expeditions, ethnic identity, assimilation.

\section{References}

Arhiv Rossiyskoy akademii nauk [Archive of the Russian Academy of Sciences].

Boyakova S. I. «Znatok Kolyimskogo kraya...»: N.N. Berezkin o problemah i perspektivah razvitiya Kraynego Severa [«A connoisseur of the Kolyma region ...»: N. N. Berezkin on the problems and prospects for the development of the Far North] // Yakutskiy arhiv [The Yakut archive]. - 2011. - № 3. - P. 80-82. (in Russian)

Chichlo B. Le district de Nizhnekolymski: population, renniculture, ethnicite [Nizhnekolymski district: population, renniculture, ethnicity] // Siberie II, Histoire, Culture, Litterature [Siberia II, History, Culture, Literature] / Ed. by B. Chichlo. - Paris: Institut d'Etudes Slaves, 1999. - P. 475-502. (in French)

Grigorev S. A. Obschestvenno-politicheskoe dvizhenie korennyih narodov Yakutii (konets 1980-h - 1990-e gody). - Dis. of Candidate of Historical Sciences: NEFU, 2011. - 181 p. (in Russian)

Gurvich I. S. Etnograficheskaya ekspeditsiya v Nizhne-Kolyimskiy i Sredne-Kolyimskiy rayonyi Yakutskoy ASSR v 1951 godu [Ethnographic expedition to the Lower Kolyma and Middle Kolyma regions of the Yakut ASSR in 1951] // Sovetskaya etnografiya [Soviet ethnography]. - 1952. - № 3. - P. 200-209. (in Russian) 
Donskoy F. S., Kurilov G. N., Sleptsov Ya. G. et al. Problemyi vozrozhdeniya ischezayuschih yukagirov [Problems of the revival of the disappearing Yukaghirs]. - Yakutsk: Severoved, 1996. - 140 p. (in Russian)

Filippova V. V. Yukagiryi Yakutii: dinamika demograficheskih pokazateley vtoroy polovinyi XX - nach. XXI v. [Yukaghirs of Yakutia: dynamics of demographic indicators of the second half of XX - beg. XXI c.] // Kazanskaya nauka [Kazan science]. - 2014. - № 11. - P. 39-43. (in Russian).

Johelson V. I. Brodyachie rodyi tundryi mezhdu rekami Indigirkoy i Kolyimoy, ih etnicheskiy sostav, narechie, byit, brachnyie i inyie obyichai i vzaimodeystvie razlichnyih plemennyih elementov [Wandering genera of the tundra between the Indigirka and Kolyma rivers, their ethnic composition, adverb, way of life, marital and other customs and interaction of various tribal elements] // Zhivaya starina [Live antiquity]. - 1900. - Issue 1-4. - 654 p. (in Russian)

Johelson V. I. Yukagiryi i yukagirizirovannyie tungusyi [Yukaghirs and Yukagirized Tungus]. - Novosibirsk: Nauka, 2005. 675 p. (in Russian)

Kurilov G. N. Sovremennyiy yukagirskiy yazyik [Modern Yukaghir language]. - Yakutsk: Offset, 2006 - 280 p. (in Russian) Maydel G. L. Puteshestvie po Severo-Vostochnoy chasti Yakutskoy oblasti v 1868-1870 godah [Traveling in the NorthEastern part of the Yakut region in 1868-1870]. - St. Petersburg: Imperial Academy of Sciences Publ., 1894. - 599 p. (in Russian)

Nauchnyiy arhiv Instituta etnologii i antropologii im. N. N. Mikluho-Maklaya RAN [Scientific Archive of the N. N. MiklouhoMaclay Institute of Ethnology and Anthropology of the RAS] (in Russian)

Nauchnyiy arhiv Muzeya antropologii i etnografii im. Petra Velikogo RAN [Scientific archive of the Peter the Great Museum of Anthropology and of the RAS] (in Russian)

Polevyie materialyi avtora [Field materials of the author]. $-2013 \mathrm{~g}$.

Posuh O. L. Genetiko-demograficheskoe izuchenie populyatsiy evenov i yukagirov Yakutii [Genetic-demographic study of populations of Evens and Yukaghirs of Yakutia] // Populyatsionno-geneticheskoe izuchenie severnyih narodnostey [Population-genetic study of northern nationalities]. - Novosibirsk: ICG of the SB RAS, 1992. - P. 41-65. (in Russian)

Rukopisnyiy fond Arhiva Yakutskogo nauchnogo tsentra Sibirskogo otdeleniya RAN [Handwritten Fund of the Archives of the Yakutsk Scientific Center of the Siberian Branch of the RAS].

Shadrin V. I. Transformatsiya etnicheskoy identichnosti yukagirov v sovremennyih usloviyah [Transformation of the ethnic identity of the Yukagirs in modern conditions] // Gumanitarnyie i sotsialnyie nauki [Humanities and Social Sciences]. 2014. - № 1. - P. 9-19. (in Russian)

Shirina D. A. Rossiya: nauchnoe issledovanie Arktiki. XVIII v. - 1917 g. [Russia: scientific study of the Arctic. XVIII c. 1917]. - Novosibirsk: Nauka, 2001. - 191 p. (in Russian)

Tugolukov V. A. Kto vyi, yukagiryi? [Who are you, Yukaghirs?]. - M.: Nauka, 1979. - 152 p. (in Russian)

Vinokurova L. I., Shadrin V. I. Lesnyie yukagiryi Yakutii: sostoyanie etnicheskoy kulturyi [Yukaghirs of Yakutia: the state of ethnic culture] // Mezhetnicheskie vzaimodeystviya i sotsiokulturnaya adaptatsiya narodov severa Rossii [Interethnic interactions and sociocultural adaptation of the peoples of the North of Russia]. - M.: KoLeSo, 2006. - P. 75-95. (in Russian)

Wrangel F. P. Puteshestvie po severnyim beregam Sibiri i po Ledovitomu moryu [Journey through the northern shores of Siberia and the Arctic Ocean]. - M.: Glavsevmorput' Publ., 1948. - 454 p. (in Russian)

Suleymanov A. A., Candidate of Historical Sciences, Senior Researcher

of the Department of History and Ethnosociology.

The Institute for Humanities Research and Indigenous Studies of the North, Russian Academy of Sciences, Siberian Branch.

Ul. Petrovskogo, 1, Yakutsk, Russia, 677007.

E-mail: alexas1306@gmail.com 